\title{
O EFEITO DAS ECONOMIAS \\ DE AGLOMERAÇÃO SOBRE \\ OS SALÁRIOS INDUSTRIAIS: \\ UMA APLICAÇÃO AO CASO BRASILEIRO*
}

\author{
Rangel Galinari ${ }^{* *}$
}

\author{
Marco Aurélio Crocco ${ }^{* *}$
}

Mauro Borges Lemos ${ }^{* * * *}$

\section{Maria Fernanda Diamante Basques ${ }^{* * * *}$}

RESUMO A literatura econômica tem encontrado fortes efeitos das economias de aglomeração no espaço sobre os salários urbano-industriais dos países desenvolvidos. Não há consenso se tais efeitos advêm de economias externas da especialização produtiva, da aglomeração urbana ou de ambas. A questão relevante é como os efeitos aglomerativos sobre os salários se manifestam em países de industrialização recente. Utilizando-se dados dos censos demográficos de 1991 e 2000, o trabalho investiga se, no contexto urbano-regional brasileiro, tais economias estão presentes e como influenciam os salários urbano-industriais do País. Para tanto, em primeiro lugar é feita a visualização da dotação relativa de variáveis que denotam as economias de aglomeração dos centros urbanos, juntamente com o salário médio auferido por suas PEAs industriais, por meio da análise de componentes principais. A seguir, utilizamse técnicas econométricas visando a mensurar o efeito médio de variáveis como con-

\footnotetext{
* Artigo recebido em 8 de março de 2005 e aprovado em 28 de junho de 2007.

** Tecnologista do Instituto Brasileiro de Geografia e Estatística (IBGE), e-mail: rangel.galinari@ ibge.gov.br

*** Professor do Cedeplar/UFMG, e-mail: crocco@cedeplar.ufmg.br

**** Professor do Cedeplar/UFMG, e-mail: mbl@cedeplar.ufmg.br

Especialista da Agência Nacional do Petróleo (ANP), e-mail: fbasques@anp.gov.br
} 
centração, especialização produtiva e capital humano sobre os salários industriais da amostra em questão.

Palavras-chave: economias de aglomeração; economias de escala externas; salários urbano-industriais; análise de componentes principais

Código JEL: R1 \& 8211; general regional economics

THE EFFECTS OF AGGLOMERATION ECONOMIES ON LOCAL WAGE RATES: AN APPLICATION TO BRAZILIAN MANUFACTURING

ABSTRACT The contemporary literature on urban and region economics have found strong effects of agglomerations economies in space on urban-industrial wages in developed countries. However, there is no consensus if such agglomerative effects come from either external-scale economies of productive specialization or urban agglomeration per se or from both. Our question is how these agglomerative effects on wages will take place in newly industrializing countries. We will take the Brazilian case, using the Demographic Census Database, to test if these externalscale economies exist and how are the nature of their effects on urban-industrial wages. Firstly, we will identify the relevant variables of agglomeration economies by using principal component analysis. Subsequently, we will use econometrics to test the effect of agglomeration-economy variables on the urban-industrial wages.

Key words: agglomeration economies; external-scale economies; urban-industrial wages; principal component analyses 


\section{INTRODUÇÃO}

O presente trabalho tem como objetivo avaliar em que medida as economias de aglomeração - subdivididas em economias de especialização (ou localização) e urbanização - têm impacto sobre os salários urbano-industriais em um país de industrialização recente como o Brasil.

A literatura sobre economia regional tem pesquisado a natureza e os possíveis benefícios para o desenvolvimento local das chamadas economias de aglomeração. Seus efeitos podem ser estudados por duas vias distintas: através de incrementos à produtividade do trabalho ou sobre os salários. Vários trabalhos na literatura internacional já utilizaram essas duas vias e encontraram fortes evidências de que as economias de aglomeração - pelo menos nos países desenvolvidos - têm efeitos positivos tanto para as firmas quanto para os trabalhadores.

Dada a precariedade das bases de dados disponíveis sobre a indústria brasileira, principalmente em se tratando de informações setoriais em nível municipal, a operacionalização de estudos empíricos no País que enfocam a produtividade do trabalho torna-se difícil e pouco precisa. Tendo isso em vista, busca-se aqui desenvolver um estudo que relacione as economias de aglomeração e os salários urbano-industriais.

Para dar dinamismo ao entendimento das economias de aglomeração aplicadas ao caso brasileiro, decidiu-se direcionar o estudo em dois pontos distintos do tempo: em 1991 e 2000. São anos extremos da década de 1990, marcada por importantes mudanças institucionais, políticas e, sobretudo, econômicas, no cenário brasileiro. Assim, abre-se a possibilidade de verificar se tais mudanças causaram significativas alterações nos salários industriais, em alguns de seus determinantes e de sua estrutura regional.

Para facilitar o entendimento do problema proposto, este trabalho está dividido em três seções, além desta introdução e das considerações finais. A primeira é reservada a uma revisão do referencial teórico básico, enquanto a segunda trata da metodologia e bases de dados utilizadas e a terceira discute os resultados obtidos. 


\section{ASPECTOS TEÓRICOS}

\subsection{Economias de aglomeração e a produtividade do trabalho}

As vantagens da aglomeração produtiva remontam à obra de Marshall (1985 [1890]), especialmente as externalidades advindas da especialização das firmas dentro de um aglomerado. Segundo Marshall, além das economias internas às firmas geradas pelo aumento da sua escala de produção, tem-se outra fonte de ganhos externos gerados pela escala da indústria, concentrada geograficamente.

Assim, a aglomeração gera externalidades através do relacionamento entre firmas e pessoas envolvidas nas atividades correlatas locais, o que estimula a criação, difusão e aperfeiçoamento de novas idéias - sintetizado pelo termo "spillover informacional ou de conhecimento" - , que resultam em economias externas tecnológicas para as plantas ali localizadas. A aglomeração em si pode atrair para a sua proximidade atividades subsidiárias que reduzem o custo de transporte dos insumos, matérias-primas e instrumentos. Isso, além de permitir uma maior organização do comércio, pode gerar sinergias entre os diversos segmentos da cadeia produtiva proporcionando economias pecuniárias de insumos. Marshall frisa que há também economias proporcionadas pela acumulação de experiência dos trabalhadores no mercado local, aumentando a capacitação da força de trabalho e a sua produtividade.

À luz da tríade marshalliana, ${ }^{1}$ Henderson (1999) realizou um estudo empírico no qual investigou a influência das economias externas de escala sobre a produtividade de diferentes indústrias nas Metropolitan Statistical Areas (MSAs) americanas. O autor parte de questões ainda não resolvidas na literatura: (1) se as economias de escala urbanas derivam primariamente da atividade industrial local, como em Marshall (1985 [1890]), ou da escala geral e da diversidade de todas as atividades econômicas locais, como em Jacobs (1969); (2) se as economias de escala são primariamente estáticas ou dinâmicas; ${ }^{2}$ (3) quais são os atributos do ambiente local que geram as externalidades; e (4) quais as magnitudes envolvidas.

Interessa saber também qual a principal fonte de aprendizado dos trabalhadores das plantas industriais quando as externalidades envolvem spillovers informacionais. Em outras palavras, se o processo de criação, difusão e aperfeiçoamento de idéias ocorre entre as plantas de uma mesma indústria 
ou similares; $;^{3}$ entre firmas pertencentes a setores diversos; ${ }^{4}$ ou ainda se são provenientes do mercado de trabalho via interações face-to-face, isto é, mediante a intercomunicação entre os atores envolvidos em tal mercado.

$\mathrm{O}$ artigo de Henderson apresenta evidências de que as externalidades de escala derivam da própria indústria (economias de especialização-localização/MAR). Ademais, verificou-se que tais externalidades decorrem mais dos spillovers informacionais gerados pelo número de plantas do que do mercado de trabalho. Outro ponto que se deve destacar é que os efeitos são localizados, isto é, dependem do número de plantas na cidade, e não nas regiões vizinhas — o que está de acordo com Ciccone \& Hall (1996), que também trabalharam o caso americano, e Dekle \& Eaton (1994), que se dedicaram ao caso japonês. No entanto, esses estudos não encontram evidências da presença de economias de urbanização para as atividades industriais.

Já de acordo com Jacobs (1969), não é a especialização, mas sim a diversidade de atividades (industriais e de serviços) desenvolvidas nos centros urbanos que traz contribuições à produtividade do trabalho e garante a sustentabilidade de longo prazo das economias locais. A autora utiliza um exemplo de duas cidades inglesas, Manchester e Birmingham. Após a Revolução Industrial, a primeira se especializou em tecelagem, atingiu o auge e entrou em decadência, enquanto a segunda desenvolveu atividades diversas e se tornou um dos principais centros urbanos do país. Assim, Jacobs defende que a multiplicidade de atividades desenvolvidas em um centro urbano pode servir como suporte às inovações, que, por sua vez, garantem o crescimento da produtividade do trabalho, bem como a sustentabilidade de longo prazo da cidade como centro industrial.

Conforme Wheaton \& Lewis (2002:542-543), alguns trabalhos encontraram evidências de efeitos das economias de urbanização sobre a produtividade, como Glaeser et al. (1992) para economias de urbanização tipo Jacobs; Henderson et al. (1995) para externalidades MAR e Jacobs; e Nakamura (1985) para economias de localização e urbanização. Dada tal dissonância de resultados, o presente trabalho abre espaço para a verificação da presença ou não dessas economias para o caso brasileiro.

Corroborando as teorias expressas em um trabalho anterior, de 1974, Henderson (1999) verificou que a extensão da aglomeração espacial está diretamente relacionada à grandeza das economias de escala das indústrias. 
Além disso, o trabalho evidencia que as indústrias de alta tecnologia experimentam economias de escala externas locais maiores que as tradicionais e são mais aglomeradas, como seria esperado. Vale destacar que, em relação ao dinamismo das economias de escala, o autor encontrou fortes efeitos do ambiente passado (cinco anos atrás) para as plantas de alta tecnologia, mas não encontrou evidências de que o mesmo se aplique às demais indústrias.

Todavia, a despeito das vantagens obtidas pelas firmas derivadas da concentração das atividades produtivas - tais como os encadeamentos a jusante e a montante, a presença de serviços complementares e infra-estrutura básica (como água, energia e estradas) —, não se deve perder de vista que o processo aglomerativo, ao estimular o crescimento das cidades, pode impor alguns prejuízos à população. Em outras palavras, o crescimento excessivo das cidades causa declínios ao bem-estar da população em função de problemas típicos dos grandes centros urbanos, como poluição e congestionamentos. Outra fonte de perdas de bem-estar é o preço do solo urbano, que tende a aumentar à medida que cresce a disputa pelo solo na cidade.

De fato, as economias de aglomeração, sobretudo as de urbanização, podem declinar com o crescimento das cidades de forma que as deseconomias começam a se destacar. Estas últimas podem se tornar tão intensas ante as primeiras que se abre a possibilidade de ocorrência de economias de aglomeração líquidas negativas. No entanto, Jacobs (1969) sustenta que a causa original da estagnação e decadência de uma cidade (economias externas negativas) seria sua incapacidade de manter o processo local de substituição de exportações e importações, que se interagem criando uma dinâmica urbana específica. Nessa linha de argumentação, os fatores desaglomerativos são gargalos do sistema de produção urbano (p. ex., o lixo urbano), que funcionam como mecanismo de indução para inovações produtivas de bens e serviços e, portanto, fonte potencial de novas exportações substitutivas, as quais realimentam um novo ciclo de substituição local de importações.

Admite-se, que as cidades podem atrair ou repelir atividades econômicas específicas conforme o grau das (des)economias de aglomeração que interessam a tais atividades. De acordo com Pereira \& Lemos (2002), no processo de desenvolvimento urbano de uma sociedade observam-se o surgimento, auge e declínio das economias de urbanização. Estas são crescentes a partir 
de um determinado tamanho populacional crítico do centro urbano, tornam-se máximas e tendem a decrescer a partir daí. No entanto, como sua dinâmica é dada pelas inovações de bens e serviços, o chamado tamanho crítico é uma variável móvel no tempo, pois podem surgir novas fontes de economias de urbanização expressas na mudança da base exportadora da cidade.

\subsection{As economias de aglomeração e os salários}

A abordagem dos efeitos das (des)economias de aglomeração e da concentração do mercado de trabalho local sobre o bem-estar dos trabalhadores - e, principalmente, sobre os salários nominais que os mesmos auferem - torna-se interessante quando se percebe que é errôneo inferir que os diferenciais de salários regionais representam estritamente a variabilidade da produtividade do trabalho. É importante lembrar que alguns fatores explicam os diferenciais regionais de salários, mas não necessariamente os de produtividade. Características institucionais locais, como a sindicalização e variações no custo de vida observadas entre as cidades, são exemplos claros que sustentam tal argumento.

Teorias acerca dos retornos crescentes no mercado de trabalho afirmam que as economias de aglomeração e alguns fatores desaglomerativos tendem a aumentar os salários nominais urbanos. Os efeitos das primeiras podem ser creditados a ganhos de produtividade das firmas repassados em algum grau para os trabalhadores. Já o impacto dos últimos se dá por meio de compensações à redução do bem-estar provenientes de fatores como o crescimento dos custos urbanos (i.e., transportes e aluguéis) e redução de amenidades ambientais (i.e., poluição sonora, visual e do ar). Hanson (1997) argumenta que:

para atrair trabalhadores ao centro industrial, as firmas devem compensálos pelos "custos de congestionamento" pagando-os salários relativamente altos. Já as firmas localizadas fora dos aglomerados industriais pagam salários relativamente baixos para serem compensadas pelo custo de transportar seus produtos finais ao centro industrial primaz. Ademais, os trabalhadores aceitam salários mais baixos fora dos aglomerados industriais dado que se defrontam com menores custos urbanos.

A partir dessas proposições entende-se que há a possibilidade de existência de um gradiente de salários nominais entre os centros industriais, em 
que aqueles decrescem à medida que aumenta o custo de transporte dos bens ao centro consumidor primaz. Isso significa que os salários podem estar submetidos a algum tipo de dependência espacial e serem inversamente proporcionais à distância a um centro urbano de referência.

Considerando-se um contexto de alta mobilidade do capital no espaço, os empresários encaram duas opções quanto à alocação de suas plantas produtivas: estabelecê-las em locais de salários relativamente mais altos ou mais baixos. Haja vista que a concentração de firmas nas cidades é um fato observável empiricamente - e que isso pode conduzir ao pagamento de proventos relativamente mais elevados - , pode-se dizer que os empresários só pagam salários relativamente mais altos em locais específicos porque recebem em troca alguma vantagem produtiva, como as reduções nos custos derivadas das economias externas.

Por outro lado, $\mathrm{Kim}^{5}$ (1990 apud Wheaton \& Lewis, 2002:543) defende que os ganhos provenientes do mercado de trabalho são localizados. Quando há mais trabalhadores em uma indústria ou ocupação particular em um mesmo mercado de trabalho local, a concorrência entre eles se torna um fator positivo. Com a disputa pelo emprego, os trabalhadores optam por aumentar a "profundidade" ao invés da "amplitude" do seu capital humano, gerando assim inovações e aumento da produtividade do trabalho. Wheaton \& Lewis (2002) afirmam, por sua vez, que a concorrência entre os trabalhadores e a acumulação de capital humano realizada por estes são crescentes com a própria escala dos pólos de trabalho. ${ }^{6}$ Para tornar esse argumento mais claro, os autores citam um exemplo no qual programadores de computador de uma cidade qualquer deveriam se especializar e ser cada vez mais produtivos à medida que o mercado de trabalho local se tornasse mais intenso em seus serviços. Isso, no entanto, não necessariamente ocorreria se em tal local houvesse muitos trabalhadores em outras indústrias/ocupações não correlatas. Essa diversidade de indústrias/ocupações, por sua vez, poderia gerar economias de urbanização que beneficiariam as atividades econômicas locais de uma forma geral, e não o mercado de programadores especificamente.

Incentivado por outros autores que defendem a educação como fonte de crescimento econômico, Rauch (1993) desenvolveu um estudo no qual investigou as externalidades positivas para a produção e salários, derivadas da 
acumulação de capital humano. Para ele, o fundamento microeconômico desse efeito externo é a distribuição de conhecimento e habilidades entre trabalhadores que ocorre mediante interações formais e informais. Esse comportamento influencia a produtividade e os salários indiretamente, através de melhorias tecnológicas. $\mathrm{O}$ trabalho desse autor, dividindo o capital humano em nível médio de educação e experiência da PEA, encontrou entre as MSAs americanas efeitos positivos sobre os salários.

O fato de que várias teorias e estudos empíricos defendem os impactos positivos dos retornos crescentes sobre os salários suscita uma questão: à luz dos diferenciais de salários reais entre as cidades especializadas, por que a força de trabalho, agindo racionalmente, não se concentra em sua totalidade nos centros que ofertam os maiores rendimentos? Alguns teóricos respondem que a mobilidade do trabalhador é imperfeita ou idiossincrática em função dos diferenciais de "estilo de vida" e das oportunidades que as cidades podem oferecer. A maioria dos centros urbanos especializados, principalmente os relativamente maiores, tem mais a oferecer, além dos altos salários. Opções de conforto, lazer e serviços, como restaurantes étnicos, cinemas, serviços de entrega e teatros, são mais facilmente encontrados em centros maiores. Por outro lado, perdem para as cidades menores em termos de amenidades ambientais, como o tráfego, ruídos, níveis de criminalidade e de poluição.

Analisando as (des)vantagens de se viver em um centro urbano especializado, compreende-se que o trabalhador marginal, que vive em sua região preferida em termos de estilo de vida, é indiferente entre os altos salários de uma região mais especializada e os baixos daquela em que reside. Isso conduz ao entendimento de que os trabalhadores, sob as mesmas condições de educação e experiência, ao aceitarem salários reais relativamente menores, estão agindo racionalmente em função de compensações que recebem em termos de qualidade de vida.

Rauch (1993) possui uma resposta mais simples à questão proposta. Ele explica que a migração da força de trabalho para áreas de maiores salários conduz a maiores aluguéis residenciais e comerciais. A valorização no mercado imobiliário compensa os maiores salários e permite um equilíbrio espacial entre o bem-estar da população e os custos de produção das firmas. 
Hanson (1997) assinala outras fontes dos diferenciais de salários regionais. Conforme o autor, características exógenas às regiões devem ser consideradas quando os custos de transporte são positivos. Se uma região é abundante em um determinado recurso natural, firmas intensivas no mesmo poderão aí se aglomerar. Para fazê-lo, devem estar dispostas a pagar salários relativamente mais altos, uma vez que economizam no custo de transporte das matérias-primas.

O mesmo autor também salienta o papel de algumas políticas governamentais que sublimam a atratividade relativa das regiões como pólos produtivos, podendo gerar gradientes regionais de salários. Para tanto, argumenta que o setor público, ao concentrar suas atividades em uma região particular, pode criar uma massa de consumo que, dados os custos de transporte, atrairá firmas interessadas em servir o mercado consumidor local, gerando, assim, o gradiente regional de salários. Além disso, políticas públicas podem proporcionar o mesmo gradiente ao privilegiar regiões com tarifas especiais ou por outras condições favoráveis à instalação de empresas. Exemplos claros dessa conduta são as chamadas "guerras fiscais" empreendidas por vários Estados brasileiros, cujos governantes oferecem terrenos, isenções fiscais e financiamentos com o intuito de atrair investimentos diretos para o seu território.

\section{METODOLOGIA E BASES DE DADOS}

\subsection{0 recorte regional, bases de dados e variáveis}

O critério para a delimitação regional deste estudo leva em consideração a conformação das relações interurbanas da rede de cidades brasileiras, bem como as mudanças observadas nas últimas décadas em se tratando da distribuição espacial da indústria no território nacional. Conforme um dos autores que tratou desse tema, Diniz (1994), a partir dos anos 1970 a região metropolitana de São Paulo (RMSP) começa a exibir deseconomias de aglomeração pari passu à criação de economias de aglomeração em outros centros urbanos do País. Em um primeiro momento, a reversão da polarização da RMSP ocorreu com uma relativa dispersão dos investimentos e da produção industrial para várias regiões do País. Todavia, graças à ênfase cada vez maior em indústrias de alta tecnologia e ao relativo declínio e fracasso das políticas regionais e dos investimentos realizados pelo Estado, o processo de 
desconcentração tendeu a se enfraquecer e a se circunscrever ao grande polígono em torno do Estado de São Paulo. ${ }^{7}$

Notoriamente, as cidades médias ${ }^{8}$ - e mesmo as grandes que ainda não exibem economias de aglomeração líquidas negativas — tendem a ser favorecidas na decisão dos empresários sobre a alocação de novos investimentos produtivos, já que possuem infra-estrutura mínima para o suporte das atividades industriais, como transportes, energia, oferta de serviços modernos, concentração de centros de pesquisa, capital humano relativamente desenvolvido e mercado consumidor denso. ${ }^{9}$ Uma vez que são nesses centros urbanos que as economias de aglomeração tendem a se mostrar com maior vigor e que, portanto, foram nos mesmos que os benefícios da desconcentração da RMSP tenderam a se concentrar, mostra-se interessante focar o estudo dos retornos crescentes nesse tipo de cidade.

Sendo assim, o presente trabalho investiga as economias de aglomeração e seus possíveis reflexos sobre os salários industriais pagos nas cidades médias e grandes que estruturam a malha urbana brasileira, isto é, nos 84 meso e macropólos brasileiros, ${ }^{10}$ definidos na regionalização econômica de Lemos et al. (2003).

Para tal, foram usadas duas bases de dados distintas: os censos demográficos 1991 e 2000 (microdados da amostra) do Instituto Brasileiro de Geografia e Estatística (IBGE), adotados como base de dados principal, e a Relação Anual de Informações Sociais 1991 e 2000 (Rais), disponibilizada pelo Ministério do Trabalho e Emprego, como complementar. Deve-se ressaltar que foram mantidas, no banco de dados, apenas informações de pessoas empregadas na indústria e remuneradas - com ou sem carteira assinada.

Foram as seguintes as variáveis selecionadas:

Salário/hora médio industrial: Obtido através da média da variável "rendimento bruto na ocupação principal" do mês de referência de cada um dos censos demográficos — agosto de 1991 e julho de 2000 — dividida previamente pelo total de horas trabalhadas/mês.

Anos de estudo da PEA industrial: A fim de incorporar uma medida do capital humano ao modelo, foi utilizada a média dos anos de estudo PEA ocupada dos censos demográficos.

Concentração industrial: A concentração do mercado de trabalho industrial local, variável importante no contexto das economias de aglomeração 
por exprimir a idéia de densidade e escala da indústria dos mesopólos, foi obtida dos censos demográficos através do cálculo da participação relativa do emprego industrial local sobre o nacional.

Especialização produtiva local (HH): Para investigar se é a diversidade ou a especialização produtiva das cidades que influencia de forma positiva os salários locais, foi construído, a partir dos censos demográficos, um índice que demonstra a variabilidade da especialização produtiva entre as cidades. Tal indicador, conhecido por Hirschman-Herfindal (HH) ou Elison-Glaeser ajustado, conforme Henderson (1999), é obtido como segue:

$$
H H i=\sum_{j=1}^{n}\left[\left(E_{i j} / E_{i}\right)-\left(E_{j} / E_{p}\right)\right]^{2}
$$

Em que:

$E_{i j}=$ Emprego na cidade $i$ no setor $j$;

$E_{i}=$ Total do emprego industrial na cidade $i$;

$E_{j}=$ Emprego nacional no setor $j$;

$E_{p}=$ Total do emprego industrial no país;

$n=1,2,3, \ldots, 27$ são os setores industriais.

Assim, a indústria de uma cidade $i$ qualquer é perfeitamente diversa quando seu $H H=0$. Por outro lado, o limite, ou seja, $H H_{\mathrm{i}} \rightarrow 2$, indica que a cidade é completamente especializada.

Emprego em grandes empresas: Para investigar se são as economias externas, internas, ou ambas que se destacam em determinadas cidades e influenciam os salários industriais, foi criada uma variável, para a análise de componentes principais (ACP), que expressa a participação do emprego em grandes empresas industriais ${ }^{11}$ em relação ao total da indústria local. Para tal, foram usados os dados de emprego formal da Rais 1991 e 2000.

É importante sublinhar que algumas variáveis importantes e que enriqueceriam o estudo foram omitidas em função da carência de dados para as cidades estudadas. Bons exemplos nesse sentido são a sindicalização da PEA e o diferencial de custo de vida entre centros urbanos. No entanto, para reduzir em algum grau o problema da omissão do custo de vida, optou-se pelo uso da variável "rendimento bruto na ocupação principal" em detrimento 
do "rendimento total na ocupação principal". Ao contrário desta última, a primeira variável é isenta dos valores que o trabalhador recebe para compensar em parte o custo de vida urbano, como vales-transporte e tickets alimentação, o que deixa mais apurada a relação entre as economias de aglomeração e os salários.

\subsection{Métodos de análise}

A análise de componentes principais (ACP) é um dos métodos multivariados que têm por objetivo condensar uma variedade de informações a fim de torná-los mais inteligíveis, isto é, transformar um grande número de variáveis correlacionadas em uma pequena quantidade de componentes pouco correlacionados, mas que levam em conta a maior parte da variância dos dados originais. ${ }^{12}$ Neste estudo, a técnica foi usada para mostrar como eram as dotações relativas, em 1991 e 2000, de algumas variáveis substitutas ao capital humano (empregado na indústria), às economias de aglomeração e às economias de escala interna entre os mesopólos brasileiros. Dessa forma, torna-se possível entender quais atributos poderiam influenciar de forma positiva ou negativa os salários das cidades em questão.

Foi utilizado também um modelo econométrico com o intuito de estimar equações de salários para os anos 1991 e 2000. Estas colaboram para o entendimento das correlações (e suas intensidades) de algumas variáveis relevantes de economias de aglomeração e capital humano em relação aos salários da indústria dos mesopólos brasileiros. A modelagem assumiu a seguinte forma:

Salário/Hora $=\beta_{0}+\beta_{1}$ Anos Estudo PEA $+\beta_{2}$ Concentração Industrial + $+\beta_{3} H H+\varepsilon$

\section{ECONOMIAS DE AGLOMERAÇÃO E SALÁRIOS} INDUSTRIAIS NOS MESOPÓLOS BRASILEIROS

\subsection{Análise multivariada: os mesopólos brasileiros quanto às suas dotações de atributos representativos das economias de aglomeração}

Sabe-se que as diferentes dotações regionais de atributos representados por variáveis de cunho econômico e social podem impactar os salários industriais e podem explicar, em grande medida, a heterogeneidade espa- 
cial da renda. A análise de componentes principais possibilita o entendimento da distribuição de tais variáveis entre as cidades em questão, bem como o posicionamento das mesmas quanto aos salários médios que suas PEAS auferem.

Das combinações lineares das variáveis salário/hora industrial médio, anos de estudo da PEA, concentração industrial, especialização produtiva local $(H H)$ e percentual de empregados em grandes empresas, para os anos 1991 e 2000 nos mesopólos, foram gerados os componentes principais através do método computacional SAS 8.0. Deve-se frisar que a maior parte da variância acumulada da nuvem de pontos - 71\% em 1991 e $75 \%$ em 2000 - pode ser explicada pelos dois primeiros componentes. Isso torna relativamente fácil a análise conjunta dos resultados em um gráfico de duas dimensões, em que se plotam os dois componentes de maior variância e as cidades em estudo.

A tabela 1 traz os autovetores (ou coeficientes das combinações lineares) obtidos a partir da matriz de correlação das variáveis originais que indicam qual a importância de cada uma das variáveis nos dois primeiros componentes. Nota-se que há uma relativa estabilidade dos coeficientes encontrados para os dois anos, de onde se conclui que a interpretação a ser feita quanto às características próprias de cada componente deve ser a mesma para cada ano. Para ser mais preciso, de acordo com os coeficientes, tem-se no componente 1 uma evidente influência dos salários/hora médios, dos anos de estudo da PEA e da concentração industrial como fatores explicativos da maior parte da dispersão total da nuvem de pontos. Sendo assim, pode se dizer que o componente 1 , o do "desenvolvimento urbano-industrial", mostra a dotação relativa de capital humano da PEA concomitantemente à importância das cidades como centros industriais consolidados, ${ }^{13}$

Tabela 1: Coeficientes das combinações lineares da ACP

\begin{tabular}{lcccc}
\hline \multirow{2}{*}{ Variáveis } & \multicolumn{2}{c}{1991} & \multicolumn{2}{c}{2000} \\
\cline { 2 - 5 } & Prin1 & Prin2 & Prin1 & Prin2 \\
\hline Salário/hora médio industrial & 0,6117 & $-0,0233$ & 0,6212 & $-0,0324$ \\
\hline Anos de estudo da PEA & 0,5963 & 0,0484 & 0,6135 & $-0,0063$ \\
\hline Concentração industrial & 0,3693 & $-0,0424$ & 0,3589 & $-0,1494$ \\
\hline Especialização local (HH) & $-0,2595$ & 0,7013 & $-0,1601$ & 0,7253 \\
\hline Emprego em grandes empresas & 0,2579 & 0,7096 & 0,2886 & 0,6712 \\
\hline
\end{tabular}

Fonte: Elaboração dos autores. 
onde se presume a existência de economias aglomerativas de urbanização, correlacionadas com salários pagos mais elevados em relação à média dos mesmos. O segundo componente é o da "cidade-empresa", em que se destacam a especialização produtiva e o percentual da força de trabalho empregada em grandes empresas. A interpretação desse componente, de forma conjunta ao primeiro, torna possível entender quais cidades especializadas podem ter sido beneficiadas por economias de especialização e/ou economias de escala internas às firmas.

Na figura 1 estão plotados os dois primeiros componentes principais e os mesopólos para o ano 1991. O ponto zero indica a posição média de ambos os componentes, e assim, à medida que as cidades se encontram afastadas de tal posição, maior é a força, positiva ou negativa, atribuída à característica dos centros urbanos para cada um dos componentes. Por exemplo, no componente 1, quanto mais distantes do ponto zero (para cima) se localizam as cidades, pode-se dizer que maiores são a concentração industrial, os salários e a escolaridade da PEA nesses centros. Sendo assim, a visualização da posição de cada cidade nos dois eixos torna possível identificar se as mesmas exibem ou não salários acima da média do conjunto total e quais dotações de atributos podem ter contribuído para tal posicionamento.

É possível perceber que as cidades localizadas no quadrante 1 exibiam, em 1991, especialização produtiva local e emprego em grandes empresas acima da média da amostra. No mesmo quadrante têm-se altos salários e alta escolaridade da PEA, bem como grande concentração da atividade industrial. Portanto, as cidades aí localizadas eram dotadas, em 1991, de um parque industrial denso em termos nacionais e coordenado por pelo menos uma grande empresa. Apresentavam também capital humano relativamente capacitado e alta especialização produtiva local - cenário típico das "cidades-empresa" monoindústrias (ou monocadeias). Dadas todas essas características que, teoricamente, trazem benefícios à produtividade do trabalho, e visto que os salários dessas cidades são relativamente altos, há sinais de que as economias de aglomeração se faziam presentes. Nota-se, no entanto, que os centros mais especializadas desse quadrante - Volta Redonda, com a metalurgia; Blumenau, com a indústria têxtil/vestuário; e Manaus, com a eletrônica — pagavam salários relativamente menores que os de cidades menos especializadas, mas que possuíam força de trabalho mais qualificada 
e uma maior concentração industrial — caso de São José dos Campos e Campinas. Portanto, há aí um indicativo de que, entre as cidades estudadas, os salários são mais sensíveis a economias externas provenientes da concentração de indústrias diversificadas (economias de urbanização), conjugadas com níveis educacionais elevados, do que a economias de escala internas e de especialização.

Em contraposição ao quadrante 1 da figura 1, as cidades localizadas no quadrante 3 possuíam, em 1991, condições relativamente menos favoráveis de industrialização, em se tratando de economias de escala externas, internas, de especialização e capacitação da PEA. Podem, portanto, ter sido penalizadas em termos de produtividade do trabalho, cujo menor nível pode ter resultado na oferta de baixos salários. As cidades aí localizadas são, em geral,

Figura 1: Os componentes principais de 1991

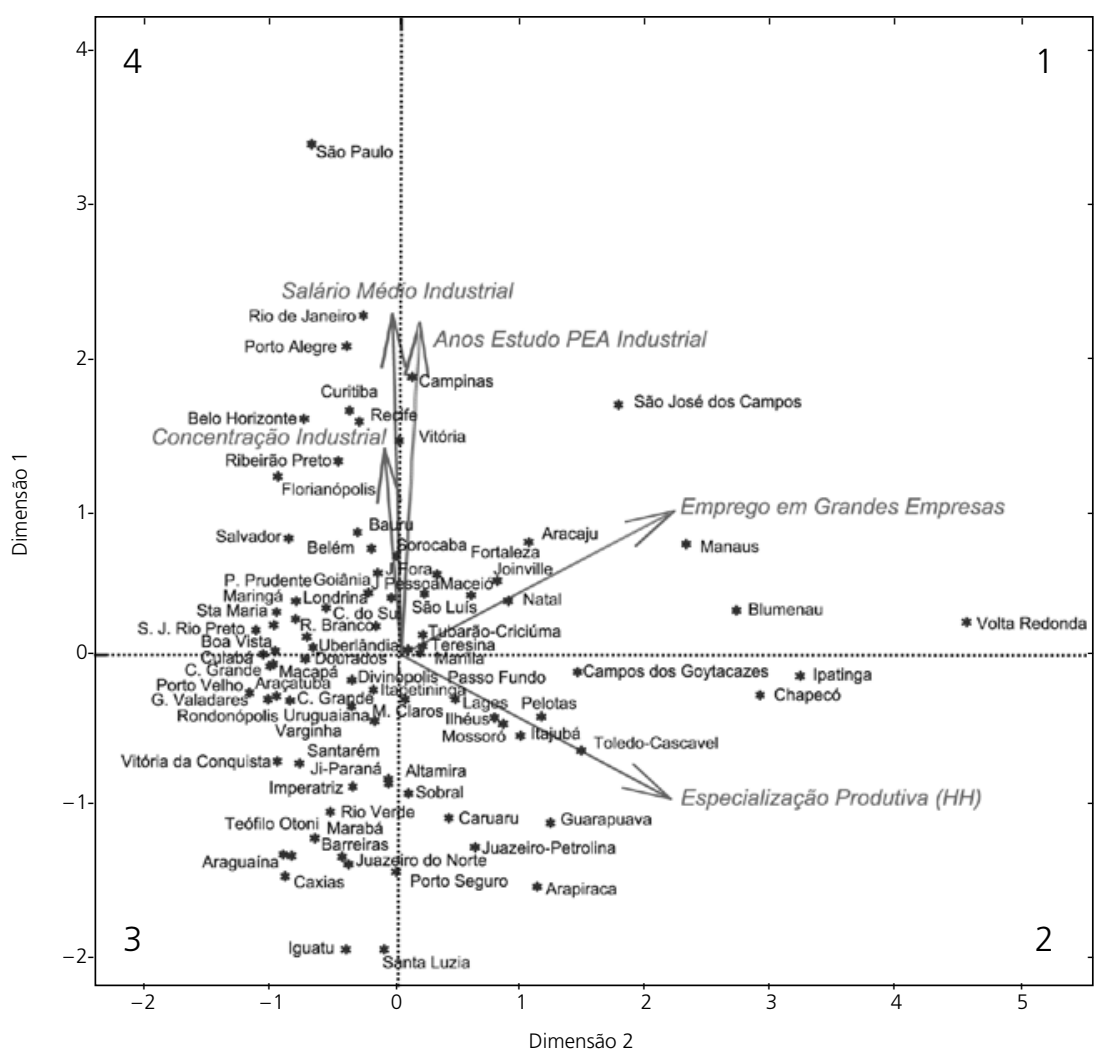


pertencentes a áreas de menor tradição industrial das regiões Norte, Nordeste e Centro-Oeste. Nota-se que a maioria dos mesopólos mineiros do entorno de Belo Horizonte, caracterizados por baixo dinamismo industrial, como Divinópolis, Governador Valadares, Teófilo Otoni e Montes Claros, também se encontram aí.

Já as cidades localizadas no quadrante 4 demonstravam possuir PEAs relativamente mais qualificadas e maior peso industrial, o que, por sua vez, pode ter induzido as mesmas a apresentarem alta produtividade do trabalho e, logo, maiores salários. Deve-se destacar que estão aí as grandes metrópoles brasileiras - São Paulo, Rio de Janeiro, Porto Alegre, Belo Horizonte, Curitiba, Salvador, Recife e Belém - e cidades médias que notoriamente têm apresentado taxas de crescimento sustentado há algumas décadas como Ribeirão Preto, Londrina, Florianópolis, Caxias do Sul e Uberlândia. Pode-se, então, inferir que os altos salários são, em parte, derivados de compensações pelos maiores custos urbanos (caso das metrópoles) ou elevadas taxas de crescimento econômico (caso das cidades médias). Os grandes centros geralmente são dotados de melhor infra-estrutura, como transportes e comunicações, centros de pesquisa, universidades e serviços modernos, que amparam as atividades produtivas. Ademais, a diversidade de atividades desenvolvidas nesses centros - o que é indicado pela localização na parte negativa do componente da especialização — abre espaço para maior integração entre os elos das cadeias produtivas. Conseqüentemente, esses grandes centros possivelmente ficam sujeitos a economias de urbanização que podem elevar tanto a produtividade do trabalho como os salários. Mais interessantes são as cidades médias dinâmicas, que corroboram a tese de Jacobs (1969) de que a diversificação produtiva é uma alavanca de desenvolvimento sustentado mais poderosa do que a especialização monoindústria (ou monocadeia), que limita, no longo prazo, a divisão intra-urbana do trabalho.

Por fim, o quadrante 2 reúne as cidades especializadas mas pouco representativas no conjunto da indústria nacional - em sua maioria centros onde há grande dedicação a setores tradicionais intensivos em força de trabalho de baixa qualificação. Nesse conjunto de características, os fatores pouco favoráveis à produtividade se destacam de forma a causar perdas ao trabalhador, em se tratando de remuneração. 
É interessante deixar claro que os salários possuem uma interpretação dual quando se trata de economias e deseconomias de aglomeração. Como frisam Pereira \& Lemos (2002):

de um lado reflete o custo da força de trabalho empregada, em si uma força repulsiva desaglomerativa, mas reflete, de outro lado, o poder aquisitivo elevado do mercado local, cujo efeito renda gera poder de encadeamento para trás via demanda interna, considerado na literatura um importante fator endógeno de retroalimentação de economias de escala interna e externa às firmas ali localizadas (Fujita et al. 1999) e, portanto, uma força de atração.

Sendo assim, os salários relativamente baixos se, por um lado, são considerados como uma vantagem competitiva para a atração de indústrias, por outro, representam baixo poder de compra do mercado consumidor e contribuem pouco para o aumento da produtividade local.

A partir da figura 2, que mostra o resultado da ACP para o ano 2000, percebe-se que uma década de mudanças na economia brasileira alterou mais a especialização produtiva entre as cidades observadas do que a hierarquia salarial propriamente dita, já que, comparando as figuras 2 e 3, nota-se que houve pouco movimento no eixo do componente 1 por parte da maioria das cidades que ali estavam, enquanto no componente 2 as modificações foram mais visíveis.

Alguns dos mesopólos que mais se destacam em termos de melhoria na posição salarial são Volta Redonda, Ipatinga, Itajubá, Varginha e Passo Fundo. As duas primeiras são sedes de grandes empresas metalúrgicas, CSN e Usiminas respectivamente, que passaram por grande reestruturação interna em função das privatizações, tornando seus processos produtivos racionalizados e mais intensivos em força de trabalho qualificada. Tais empresas terceirizaram vários serviços cuja força de trabalho era caracterizada por baixa qualificação, como limpeza e segurança, e mantiveram em seus quadros os funcionários especializados - conseqüentemente, mais caros -, o que contribuiu para a elevação dos salários médios observados no setor industrial das cidades em que estão instaladas. Em outras palavras, o processo de terceirização significou também terciarização, com a passagem de trabalhadores do emprego industrial para a área de serviços ligados à produção. Isso, em parte, contribuiu para a elevação do salário industrial médio simples- 
Figura 2: Os componentes principais de 2000

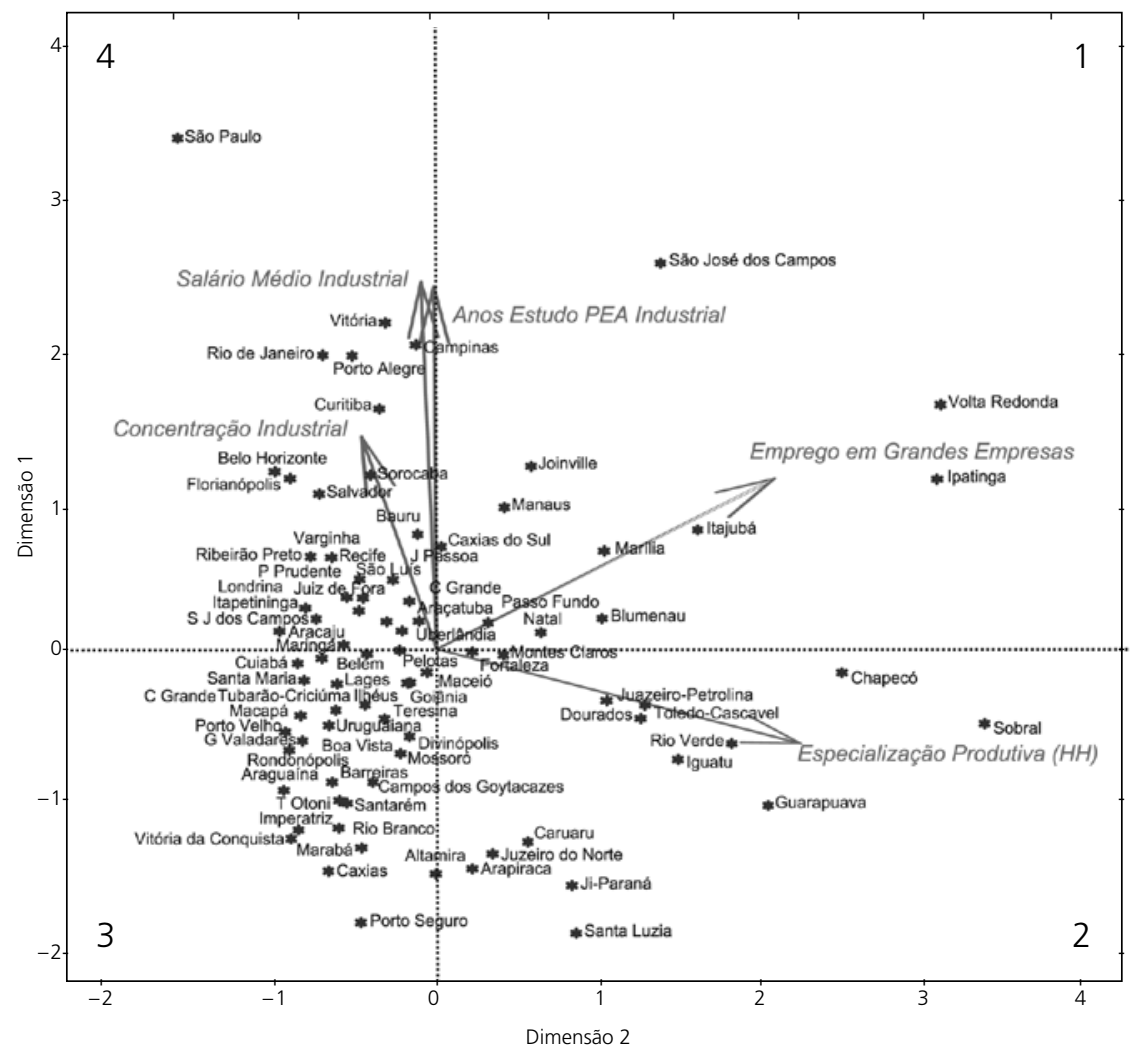

mente em função da reclassificação de vários trabalhadores do setor secundário para o terciário.

Todavia, deve-se também considerar que, por meio de reformas, a produtividade dessas empresas tendeu a aumentar de tal forma que a cidade de Ipatinga transitou de uma situação de salários relativamente baixos para salários acima da média nacional, enquanto Volta Redonda passou a contar também com uma melhoria em termos salariais.

Já as duas cidades do sul de Minas - Itajubá e Varginha — foram beneficiadas durante a década de 1990 por trasbordamentos da região metropolitana de São Paulo e investimentos em educação, tornando-as mais suscetíveis a economias externas que provocaram o deslocamento para uma 
situação na qual os salários da PEA industrial receberam alguma compensação. Já a cidade de Passo Fundo (RS) não passou por significativas mudanças em sua estrutura produtiva. Todavia, esse é um centro de referência regional por sediar uma importante e representativa universidade comunitária (a UPF), de forma que a cidade pode ter sido contemplada com melhoria salarial em função do aumento da capacitação de sua força de trabalho.

Em relação ao componente da especialização e da participação do emprego em grandes empresas, mudanças importantes ocorreram sem, contudo, alterar de forma significativa os salários das cidades que se tornaram mais especializadas. Por exemplo, os mesopólos nordestinos de Sobral (calçados), Iguatu (calçados), Santa Luzia (móveis e indústrias diversas) e Petrolina-Juazeiro (agroindústria); o de Rio Verde (alimentos e bebidas), em Goiás, e o de Ji-Paraná (produtos de madeira), em Rondônia, transitaram de uma situação de especialização relativamente baixa para alta. Entretanto, os salários pagos nas mesmas não sofreram grandes elevações.

Diniz \& Basques $(2002,2003)$ evidenciam os fatores que tornam claro o entendimento do processo que conduziu a tal situação no caso dos mesopólos nordestinos. Conforme esses autores, a abertura econômica dos anos 1990 expôs rapidamente a indústria brasileira à concorrência de bens importados, produzidos com estruturas de custo mais favoráveis que as nacionais. Soma-se a isso a intensificação da concorrência internacional em alguns mercados externos, antes cativos dos produtos brasileiros - a exemplo da grande inserção dos calçados chineses nos EUA —, que impôs à indústria nacional uma rápida necessidade de redução de custos e diversificação produtiva.

Tendo isso em vista, alguns setores tradicionais, como calçados, têxteis e confecções - aos quais se pode atribuir alta mobilidade ao seu capital, dado que sua localização não é necessariamente orientada por matérias-primas —, decidiram migrar para a região Nordeste, ou lá instalar novas plantas produtivas em função da oferta de pesados incentivos fiscais e de força de trabalho abundante e barata.

A cidade de Sobral (CE), que de 1991 a 2000 deu um grande salto em direção à especialização, conforme as figuras 2 e 3 , é um claro exemplo do fenômeno migratório de empresas do setor calçadista na década passada. Em 1993, tal cidade recebeu uma planta da Grendene que atualmente em- 
prega em torno de nove mil trabalhadores. Outras grandes indústrias do setor de calçados de São Paulo e do Rio Grande do Sul também instalaram plantas no Nordeste, como a Dakota, Azaléia, Alpargatas, dentre outras (Garcia, 2001:100, ${ }^{14}$ Santos et al., 2002, ${ }^{15}$ apud Diniz \& Basques, 2003).

Também baseada em incentivos fiscais e força de trabalho barata, ocorreu na década de 1990, uma intensa migração de empresas do setor têxtil/ confecções do Centro-Sul para a região Nordeste. Os fluxos da indústria têxtil beneficiaram principalmente os Estados do Ceará, Paraíba e Rio Grande do Norte, enquanto os de confecções se concentraram no Ceará, Rio Grande do Norte, Pernambuco e Piauí. Mas, ao contrário do setor calçadista, que passa a ter a região Nordeste como um pólo complementar ao do Sul/Sudeste, a indústria têxtil a teve como foco de relocalização; como parte de uma estratégia de redução de custos para tornar o setor competitivo nos mercados nacional e internacional.

Deve-se sublinhar que as migrações recentes de empresas do Centro-Sul brasileiro para o Nordeste não se enquadram no que Diniz (1994) e Diniz \& Crocco (1996) explicam sobre a migração de empresas decorrente da desconcentração da região metropolitana de São Paulo. O fenômeno nordestino possui uma dinâmica distinta da referida por aqueles autores, ou seja, não se deu pela criação de economias de aglomeração espontâneas em suas cidades - fato corroborado pelo não-crescimento significativo dos salários das cidades nordestinas quando se comparam as ACPs de 1991 e 2000. À grande quantidade de força de trabalho barata foi somada a possibilidade de redução do emprego formal e a alta oferta de incentivos fiscais como estratégia competitiva de grande parte das empresas que se instalaram no Nordeste. Portanto, o fenômeno foi baseado em "fatores competitivos espúrios" ${ }^{16}$ o que pode constituir uma ameaça à sustentabilidade de longo prazo do atual modelo de desenvolvimento regional nordestino.

Da mesma forma que se visualiza, a partir das figuras 2 e 3 , a evolução de algumas cidades em relação aos salários pagos à PEA industrial, percebe-se que alguns centros urbanos fizeram o caminho contrário, ou seja, transitaram dos quadrantes superiores para os inferiores. São os casos de importantes cidades, como Belém, Goiânia e Fortaleza. Por meio de uma análise exploratória dos dados foi possível identificar uma queda na escolaridade da força de trabalho industrial das duas primeiras, que, por conseguinte, sina- 
liza que a qualidade da PEA ingressante no mercado de trabalho em tais localidades durante a década de 1990 é relativamente inferior àquela que veio substituir (aposentados) e/ou complementar. Ademais, de acordo com os dados das PNADs 1992 e 1999, a sindicalização no mercado de trabalho do setor industrial da região metropolitana de Belém caiu de 35\% para $24 \%$, o que de fato pode ter contribuído para o fenômeno. Já a análise dos dados da cidade de Fortaleza revela que a mesma teve um crescimento relativo do emprego industrial abaixo da média observada nos demais municípios da amostra. Sua região metropolitana também exibiu um pequeno retrocesso de $26 \%$ para $24 \%$ da sindicalização da PEA industrial, conforme os dados da PNAD, o que também é um fator relevante, embora Fortaleza tenha sido local de instalação de empresas nas migrações referidas supra.

\subsection{Correlações entre economias de aglomeração e os salários urbanos}

Com o objetivo de demonstrar a correlação e a intensidade do relacionamento entre as variáveis de economias de aglomeração/capital humano e os salários pagos na indústria dos mesopólos brasileiros, foram realizadas regressões cross-section para os anos 1991 e 2000.

A tabela 2 apresenta os resultados obtidos através do software Econometric Views, da estimação das equações de salários de 1991 e 2000 via MQO. Ambas se mostraram isentas de multicolinearidade e autocorrelação espacial, mas as estimações para o ano 2000 apresentaram heterocedasticidade, justificando o uso da matriz de variâncias e co-variâncias de White (Greene, 2003). Vale frisar que os testes para a autocorrelação espacial, empreendidos através do software SpaceStat 1.91, utilizaram matrizes de contigüidade de primeira ordem do tipo Rook e Queen (padronizadas ou não), em que o compartilhamento de fronteira comum entre as mesorregiões associadas a cada mesopólo foi definido como critério de vizinhança. Todos os testes contra as especificações de erro e defasagem espacial disponibilizados no SpaceStat, e já de amplo uso na literatura, rejeitaram a hipótese de autocorrelação espacial nos modelos, viabilizando as estimações pelo método dos Mínimos Quadrados Ordinários. ${ }^{17}$

Observe que todas as variáveis, dependentes e independentes, foram logaritmadas para redução da heterogeneidade dos dados e conversão dos 
Tabela 2: Regressões entre economias de aglomeração e salários urbano-industriais

\begin{tabular}{|c|c|c|c|c|c|c|c|c|}
\hline \multirow{3}{*}{ Variável explicativa } & \multicolumn{6}{|c|}{ Variável explicada: Log (salário/hora industrial médio) } & & \\
\hline & \multicolumn{2}{|c|}{ Coeficiente } & \multicolumn{2}{|c|}{ Desvio-padrão } & \multicolumn{2}{|c|}{ t de Student } & \multicolumn{2}{|c|}{ Probabilidade } \\
\hline & 1991 & 2000 & 1991 & 2000 & 1991 & 2000 & 1991 & 2000 \\
\hline Constante & 3,694 & $-1,837$ & 0,390 & 0,609 & 9,468 & $-3,014$ & 0,000 & 0,004 \\
\hline Log (anos de estudo) & 1,496 & 1,532 & 0,152 & 0,256 & 9,851 & 5,981 & 0,000 & 0,000 \\
\hline Log (concentração) & 0,048 & 0,077 & 0,024 & 0,023 & 1,979 & 3,288 & 0,052 & 0,002 \\
\hline $\log (H H)$ & $-0,076$ & $-0,092$ & 0,030 & 0,030 & $-2,510$ & $-3,083$ & 0,014 & 0,003 \\
\hline $\mathrm{R}^{2}$ ajustado 1991: & 0,787 & & & & & F-statis & 1991: & 89,497 \\
\hline $\mathrm{R}^{2}$ ajustado 2000: & 0,787 & & & & & F-statis & 2000: & 97,640 \\
\hline
\end{tabular}

coeficientes estimados em elasticidades. Como conseqüência de todos os cuidados dedicados à técnica, os modelos se encontram bem ajustados, com altos F's e $\mathrm{R}^{2}$ s, o que indica que a explicação dos mesmos é bastante confiável.

Nota-se, pelo alto valor do " $t$ de Student", que a variável "anos de estudo" da população economicamente ativa ocupada no setor industrial das cidades da amostra tem grande poder de influência sobre o diferencial de salários pagos entre tais núcleos urbanos. Portanto, observa-se aqui um respaldo às teorias que defendem o investimento em capital humano como meio de promover a produtividade do trabalho, permitindo aos trabalhadores auferirem maiores rendimentos, que, por sua vez, geram um mercado consumidor e uma economia local mais desenvolvida. Todavia, deve ficar claro que os investimentos em melhorias na capacitação da PEA só têm resultados positivos aos trabalhadores se concomitantemente são criados postos de trabalhos para absorvê-los - o que é obtido, de uma forma geral, somente com o crescimento econômico do País. De acordo com os coeficientes estimados, pode-se deduzir que o incremento salarial atribuído à PEA mais bem capacitada tornou-se maior no final da década de 1990, quando comparado ao início da mesma. Os valores estimados para 1991 mostram que uma diferença de, por exemplo, $10 \%$ na média dos anos de estudo da PEA industrial de uma cidade em relação à outra era responsável por uma variação de, em média, 14,96\% nos salários pagos entre as mesmas — em favor daquela com maior nível de escolaridade. Já para o ano 2000, o coeficiente mostra que para os mesmos $10 \%$ o diferencial de salários seria de $15,32 \%$, em média, sinalizando que a educação se mostra cada vez mais importante para alavancar a renda das famílias e as economias locais. 
A variável "concentração", por denotar a presença de expressiva atividade industrial local em relação à nacional, pode ser entendida como representante das economias de aglomeração (escala externa), sobretudo as de urbanização. Sendo assim, vê-se que, tanto para o ano 1991 quanto para o 2000, as economias de aglomeração se mostraram significativamente presentes - em média - nos mesopólos brasileiros. Conforme os coeficientes estimados, uma cidade da amostra com peso industrial $100 \%$ maior que uma outra teria no ano 1991, em média, salários 5\% mais altos, enquanto em 2000 os mesmos seriam, em média, 8\% superiores. Conclui-se que as economias de aglomeração se tornaram mais intensas no correr da década. Tal fato pode indicar que a "desconcentração concentrada" da RMSP, explicada em Diniz (1994), tornou algumas cidades do Centro-Sul do Brasil mais representativas em termos de peso industrial. Isso proporcionou o crescimento das economias de aglomeração nas cidades beneficiadas pelos transbordamentos de São Paulo.

A análise da última variável, o índice de Hirschman-Herfindal $(\mathrm{HH})$ que exprime o quão especializada em uma determinada atividade industrial é uma cidade —, é, dentre as três do modelo, a mais delicada. Por apresentar sinal negativo, o seu coeficiente sinaliza que quanto mais especializado é um centro urbano em determinada atividade produtiva, em média, menores são os salários pagos no mesmo. Esse resultado contraria várias teorias acerca das economias de especialização (ou localização), mas está em consonância com a teoria de Jacobs (1969), que afirma que é a diversidade, e não a especialização local, que, por permitir a criação de sinergias entre os diversos elos do sistema produtivo urbano (bens e serviços), induz a geração de inovações e de retornos crescentes, que, por sua vez, podem trazer benefícios salariais aos trabalhadores.

Percebe-se pelo crescimento do coeficiente do $H H$ estimado no inicio e no fim dos anos 1990 que, em média, a especialização produtiva local tornou-se um fator de prejuízo à PEA em se tratando da diferenciação dos salários pagos entre os mesopólos brasileiros. Tal fato certamente está ligado a mudanças na distribuição espacial da indústria, principalmente das tradicionais, a partir da abertura da economia brasileira. Uma vez que a estratégia de redução de custos de muitos empresários foi deslocar suas firmas para regiões de força de trabalho barata, como as cidades nordestinas, vários 
centros urbanos se tornaram mais especializados durante a década, embora mantendo baixas as suas remunerações médias.

A tabela 3 exibe, para o ano 2000, as cidades da amostra que apresentaram os maiores $H H s$, o setor em que são especializadas e a razão do salário/ hora médio do setor em que são especializadas em relação aos salários

Tabela 3: Cidades com maior $\boldsymbol{H H}$, setores em que são especializadas e os salários/hora nesses setores em relação aos demais, 2000

\begin{tabular}{|c|c|c|}
\hline Mesopólo & Setor com maior $\mathrm{HH}$ & $\begin{array}{c}\text { Salário } \\
\text { setor espec./ } \\
\text { demais setores }\end{array}$ \\
\hline Natal & Fabricação de produtos têxteis/artigos do vestuário & 0,39 \\
\hline Fortaleza & Confecção de artigos do vestuário e acessórios & 0,46 \\
\hline Marília & Fabricação de produtos alimentícios e bebidas & 0,75 \\
\hline Caruaru & Confecção de artigos do vestuário e acessórios & 0,58 \\
\hline Joinville & $\begin{array}{l}\text { Fabricação de produtos alimentícios e bebidas/ } \\
\text { máquinas e equipamentos }\end{array}$ & 0,82 \\
\hline Montes Claros & Fabricação de produtos têxteis & 0,75 \\
\hline Santa Luzia & Fabricação de móveis e indústrias diversas & 0,64 \\
\hline Blumenau & Fabricação de produtos têxteis/artigos do vestuário & 0,85 \\
\hline Toledo-Cascavel & Fabricação de produtos alimentícios e bebidas & 0,88 \\
\hline Dourados & Fabricação de produtos alimentícios e bebidas & 0,87 \\
\hline Sobral & $\begin{array}{l}\text { Preparacão de couros e fabricação de artefatos de couro, } \\
\text { artigos de viagem e calçados }\end{array}$ & 0,86 \\
\hline Guarapuava & Fabricação de produtos de madeira & 0,89 \\
\hline Cariri-Juazeiro do Norte & $\begin{array}{l}\text { Preparacão de couros e fabricação de artefatos de couro, } \\
\text { artigos de viagem e calçados }\end{array}$ & 0,87 \\
\hline Chapecó & Fabricação de produtos alimentícios e bebidas & 0,96 \\
\hline Manaus & Fabricação de máquinas, aparelhos e materiais elétricos & 0,96 \\
\hline Ji-Paraná & Fabricação de produtos de madeira & 0,98 \\
\hline Itajubá & $\begin{array}{l}\text { Fabricação e montagem de veículos automotores, } \\
\text { reboques e carrocerias }\end{array}$ & 1,01 \\
\hline Iguatu & $\begin{array}{l}\text { Preparacão de couros e fabricação de artefatos de } \\
\text { couro, artigos de viagem e calçados }\end{array}$ & 1,03 \\
\hline Altamira & Fabricação de produtos de madeira & 1,17 \\
\hline Passo Fundo & Fabricação de máquinas e equipamentos & 1,21 \\
\hline Rio Verde & Fabricação de produtos alimentícios e bebidas & 1,50 \\
\hline Caxias do Sul & $\begin{array}{l}\text { Fabricação e montagem de veículos automotores, } \\
\text { reboques e carrocerias }\end{array}$ & 1,60 \\
\hline Volta Redonda & Metalurgia básica & 1,40 \\
\hline$\overline{\text { São José dos Campos }}$ & $\begin{array}{l}\text { Fabricação e montagem de veículos automotores, } \\
\text { reboques e carrocerias/outros equipamentos de transporte }\end{array}$ & 1,61 \\
\hline Ipatinga & Metalurgia básica & 2,24 \\
\hline
\end{tabular}

Fonte: IBGE - Censo demográfico 2000 (microdados da amostra). Elaboração dos autores. 
pagos nos demais setores industriais presentes em cada centro. É possível perceber que grande parte dos municípios apresenta, no setor em que são especializados, salários inferiores aos das demais atividades industriais desenvolvidas em seu parque industrial. Além disso, a maioria dos mesopólos com tais características empreende atividades em áreas tradicionais, como couro, calçados, fiação, tecelagem, confecção e produtos de madeira, nas quais as economias internas de escala tendem a ser menores que em setores tecnologicamente mais avançados — como explicitado em Henderson (1999) —, a exemplo da metalurgia em Volta Redonda e Ipatinga e a fabricação de aeronaves em São José dos Campos, cidades nas quais a relação salarial é superior a 1.

Por fim, vale frisar que os arranjos produtivos típicos dos países periféricos, como o Brasil, são em sua maioria classificados como informais. Nesse tipo de arranjo, geralmente há baixo networking entre as firmas, pouco compartilhamento de informações e fracos encadeamentos, tanto a jusante quanto a montante. Daí, pode-se dizer que a maioria dos mesopólos brasileiros com alta especialização produtiva não se enquadra nas definições mais refinadas de clusters, entendidos como arranjos competitivos e ao mesmo tempo cooperativos. Dada a baixa cooperação existente na maioria dos mesopólos brasileiros, pode-se concluir que as economias de especialização dificilmente se fariam presentes nos mesmos, o que pode ser observado neste trabalho.

\section{CONSIDERAÇÕES FINAIS}

No Brasil, a década de 1990 foi palco de importantes mudanças no cenário político e econômico, que, conforme os resultados deste trabalho, não foram suficientes nem mesmo para mitigar a grande heterogeneidade regional da estrutura salarial dos mesopólos brasileiros.

Da observação das dotações relativas de variáveis que denotam economias de aglomeração, bem como da qualidade da PEA industrial ocupada nos mesopólos, foi possível perceber quais cidades dispunham de capital humano relativamente desenvolvido e que, portanto, poderiam ser contempladas com maiores produtividade do trabalho e salários.

Os resultados também sugerem que as cidades da amostra com alta concentração industrial sem forte especialização produtiva estão sujeitas a ex- 
ternalidades de escala de urbanização - fato confirmado pelos resultados dos modelos econométricos. Tais achados se mostram de acordo com a teoria de Jacobs (1969), na qual a diversidade de atividades desenvolvidas nas cidades é o principal fator propulsor da produtividade do trabalho, dos salários e da sustentabilidade do crescimento de longo prazo da economia dos centros urbanos.

Ademais, as ACPs mostram que alguns mesopólos com especialização produtiva clara que apresentam participação relevante na indústria nacional e altos níveis de educação da PEA são contemplados por altos salários. Uma vez que nesses centros urbanos está instalada pelo menos uma grande empresa, pode-se inferir que os altos salários dos mesmos também são influenciados por economias de escala internas às firmas.

Tendo em vista que as cidades especializadas, em geral, exibem altos salários apenas quando o seu capital humano é desenvolvido e há economias de urbanização ou economias de escala internas às firmas, verificou-se que, para o caso da maioria dos mesopólos brasileiros, as economias de especialização ainda não se fazem presentes ou são muito fracas. Entretanto, não é viável dizer que as economias de especialização simplesmente não existem. O fato de haver baixa evidência a favor das mesmas nos mesopólos brasileiros é, sem dúvida, decorrente de particularidades tanto das economias regionais como da nacional. Os resultados encontrados incitam que a simples aglomeração de empresas do mesmo ramo em uma localidade não é condição suficiente para a geração de economias externas. Para que estas se desenvolvam, há a necessidade de cooperação entre os agentes envolvidos, implantação de uma rede de serviços e instituições com vistas a dar suporte às atividades industriais, gerar sinergias entre os elos das cadeias produtivas e reduzir porosidades dos processos produtivos. Para o caso brasileiro, há ainda o agravante da migração de empresas para cidades de PEA com baixa qualificação e produtividade, o que, por sua vez, criou cidades especializadas de baixos salários. Tal fato é corroborado pelos modelos econométricos estimados que, em média, acusaram relação negativa entre salários e especialização produtiva local dos mesopólos brasileiros. Conclui-se, assim, que, nos países em desenvolvimento, como o Brasil, os fatores que permitem a criação de economias de especialização são ainda fracos ou incipientes. 
Por fim, vale destacar que essa agenda de pesquisa acerca das economias de aglomeração tem, recentemente, se tornado bastante difundida na literatura internacional em função dos bons resultados que oferece, bem como pelo acesso relativamente fácil a dados sobre os mercados de trabalho localizados. O trabalho aqui apresentado está longe de dirimir as questões que permeiam as teorias sobre os retornos crescentes urbanos. Sendo assim, com vistas a lapidar ainda mais os resultados das estimações das economias de aglomeração, sugere-se que em pesquisas futuras intensifiquem-se os esforços de transposição de barreiras metodológicas inerentes a essa agenda, como a introdução de controles para os diferenciais de custos de vida nas cidades (Azzoni et al., 2000, 2003), de dotações locais de amenidades ambientais (Roback, 1982), da oferta local de serviços produtivos (Henderson, 1999), dentre outros.

\section{NOTAS}

1. Efeitos pecuniários dos encadeamentos fornecedores-usuários; mercado de trabalho e spillovers tecnológicos.

2. As externalidades estáticas são impactos na produtividade corrente, advindos de mudanças no ambiente industrial corrente, enquanto as dinâmicas estão relacionadas aos impactos na produtividade corrente provenientes das condições do ambiente passado.

3. Nesse caso as externalidades marshallianas são chamadas de economias de localização ou MAR (Marshall, Arrow, Romer) em um contexto dinâmico.

4. Caso em que as externalidades são conhecidas como economias de urbanização ou Jacobs na forma dinâmica.

5. Kim, S. Labor heterogeneity, wage bargaining, and agglomeration economies, Journal of Urban Economics, 28, 160-177, 1990.

6. Escala em termos do número de pessoas com a mesma ocupação ou empregados em uma mesma indústria.

7. Os vértices do polígono são constituídos pelas cidades de Belo Horizonte, Uberlândia, Londrina/Maringá, Porto Alegre, Florianópolis e São José dos Campos.

8. Conforme Andrade \& Serra (2001) apud Pereira \& Lemos (2002), cidades médias são aquelas com população entre 100 mil e 500 mil habitantes.

9. Diniz \& Crocco (1996:78) enfatizam que, "nos países de industrialização recente, após um histórico processo de concentração industrial em um número limitado de cidades ou metrópoles dominantes, vem ocorrendo nas últimas décadas o enfraquecimento dos processos de polarização com a emergência de áreas industriais e rápido crescimento em cidades de porte médio e pequeno". 
10. A cidade de Brasília foi excluída da análise por ser um mesopólo administrativo, de baixa representatividade industrial, cuja dinâmica de crescimento é bastante particular.

11. O Sebrae define como grandes empresas industriais aquelas que empregam mais de 500 trabalhadores. Ver em www.sebrae.com.br.

12. Sua metodologia pode ser vista com maiores detalhes em Manly, (1986 [1944]).

13. Centros industriais com grande representação perante a indústria nacional, uma vez que a variável concentração industrial resume a participação relativa de cada cidade no cômputo geral da indústria brasileira.

14. Garcia, Renato de Castro. Vantagens competitivas de empresas em aglomerações industriais: um estudo aplicado à indústria brasileira de calçados e sua inserção nas cadeias produtivas locais. Dissertação de Mestrado. Unicamp, 2001.

15. Santos, A. M. et al. Deslocamento de empresas para os Estados do Ceará e da Bahia: o caso da indústria calçadista. Rio de Janeiro: BNDES, Setorial 15, 2002.

16. Rosa, A. L.; Melo, M. C.; Santos, S. M.; Oliveira, J.; Cavalcante, J.; Sena, A. M. A indústria têxtil cearense: um estudo sobre competitividade. Fortaleza: FIEC, 1994.

17. Deve-se frisar que o diagnóstico negativo quanto à presença de spillovers espaciais é, provavelmente, função da grande distância geográfica entre os mesopólos. De fato, a mensuração de tal fenômeno é mais razoável em cidades contíguas e diretamente ligadas por infra-estrutura de transporte.

\section{REFERÊNCIAS BIBLIOGRÁFICAS}

ANDRADE, T. A.; SERRA, R. V. (Orgs.). Cidades Médias Brasileiras. Rio de Janeiro: IPEA. v. 1, 393 p., 2001.

AZZONI, C.; CARMO, H.; MENEZES, T. Índice de custo de vida comparativo para as principais regiões metropolitanas brasileiras: 1981-1999. Estudos Econômicos, v. 30, n. 1, p. 165-86, 2000.

Comparação da paridade do poder de compra entre cidades: aspectos metodológicos e aplicação ao caso brasileiro. Pesquisa e Planejamento Econômico, Rio de Janeiro, v. 33, n. 1, p. 91-126, 2003.

CICCONE, A.; HALL, R. E. Productivity and the density of economic activity. American Economic Review, v. 86, p. 54-70, 1996.

DEKLE, R.; EATON, J. Agglomeration and the price of land: evidence from the prefectures. NBER Working Paper, n. 4.781, 1994.

DINIZ, C. C. Polygonized development in Brazil: neither decentralization no continued polarization. International Journal of Urban And Regional Research, v. 18, n. 2, p. 293-314, 1994.

; BASQUES, M. F. D. Repensando a industrialização nordestina: potencialidades e desafios. Anais XXX Encontro Nacional de Economia. Nova Friburgo, RJ: ANPEC 2002. 
— - CROCCO, M. A. Reestruturação econômica e impacto regional: o novo mapa da indústria brasileira. Nova Economia. Belo Horizonte, v. 6, n. 1, p. 77-103, 1996.

FUJITA, M.; KRUGMAN, P.; VENABLES, A. The Spatial Economy: cities, regions and international trade. Cambridge, MA., The MIT Press, 1999.

—. A industrialização nordestina recente e suas perspectivas. BNB, 2003. (mimeo)

GLAESER, E. et al. Growth in cities. Journal of Political Economy, v. 100, p. 1.126-1.192, 1992.

GREENE, W. H. Econometric analysis. Nova Jersey: Prentice Hall, 2003.

HANSON, G. H. Increasing returns, trade and the regional structure of wages. The Economic Journal, v. 107, p. 13-133, 1997.

HENDERSON, J. V. The sizes and types of cities. American Economic Review, v. 64, p. 640-656, 1974.

et al. Industrial development in cities. Journal of Political Economy, v. 103, p. 1.0671090, 1995.

—. Marshall's scale economies. NBER Working Paper, n. 7358, Sep. 1999.

JACOBS, J. The Economy of Cities. Nova York: Random House, 1969.

LEMOS, M. B.; DINIZ, C.C.; GUERRA, L. P.; MORO, S. A nova configuração regional brasileira e sua geografia econômica. Estudos Econômicos, v. 33, n. 4, 2003.

MANLY, B. F. J. Multivariate statistical methods: a primer. Londres: Chapman and Hall, 1986 [1944].

MARSHALL, A. Princípios de economia: tratado introdutório. São Paulo: Nova Cultural, 1985 [1890].

NAKAMURA, R. Agglomeration economies in urban manufacturing industries: a case of Japanese cities. Jounal of Urban Economics, v. 17, p. 108-124, 1985.

PEREIRA, F. M. \& LEMOS, M. B. Cidades médias brasileiras: características e dinâmicas urbano/ industriais. Belo Horizonte: Cedeplar/UFMG, 2002. (mimeo)

RAUCH, J. E. Productivity gains from geographic concentration of human capital: evidence from the cities. Journal of Urban Economics, v. 34, p. 380-400, 1993.

ROBACK, J. Wages, rents, and quality of life. Journal of Political Economy, v. 90, p. 1.257-1.278, 1982.

WHEATON, W. C.; LEWIS, M. J. Urban wages and labor market agglomeration. Journal of Urban Economics, v. 51, p. 542-562, 2002. 